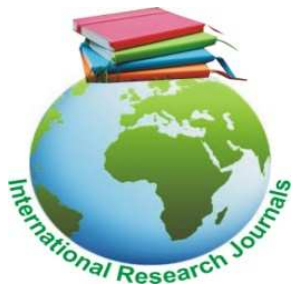

\title{
Histopathological pattern and lateral distribution of benign ovarian cysts
}

\author{
*Dr. Fatimah Zahra and Dr. Zeenat Rizvi \\ Al Ahli hospital, Ahmad bin Ali Street, Doha, Qatar \\ *Corresponding Author Email: address dr_f_zahra@hotmail.com, Phone number 0097466022637
}

\begin{abstract}
This study was carried out at Obstetrics and Gynaecology department, Al Ahli hospital, Doha, Qatar. A total of 230 women undergoing surgical intervention from 1st January 2013 to 31 st Dec 2015 had an ovarian or Paraovarian cyst. Data was collected retrospectively from clinical records and results were analyzed by IBM SPSS version 23. A total of $\mathbf{2 3 0}$ women had an ovarian or Paraovarian cyst. Benign epithelial cysts were the most common $93(40.4 \%)$ with endometriotic cysts $60(26.1 \%)$, Serous cystadenoma $22(9.6 \%)$, Mucinous cystadenoma 11(4.8\%) followed by physiological cysts $75(32.6 \%)$ with corpus luteal cysts $53(23 \%)$ and simple follicular cysts $22(9.6 \%)$. Mature cystic teratoma $39(17 \%)$, Benign sex cord stromal tumours $1(0.4 \%)$, Thecoma fibroma $2(0.9 \%)$ and borderline ovarian tumours $3(1.3 \%)$. Ovaries were bilaterally involved in $30(13 \%)$, Unilateral $200(87 \%)$. Right ovary was involved $110(47.8 \%)$ more than the left ovary $90(39.1 \%)$.Benign epithelial tumours were most common and of them endometriotic cysts were most common followed by serous cystadenoma. Right ovarian involvement was significantly greater than left ovarian involvement.
\end{abstract}

Keywords: Benign ovarian cysts, Ovarian tumours, Adnexal mass, Endometrioma, Ovarian mass

\section{INTRODUCTION}

Benign ovarian cysts are common, frequently asymptomatic and often resolve spontaneously (Zanetto et al., 2011). $90 \%$ of all ovarian tumours are benign, although this varies with age. About $7 \%$ of women have ovarian cyst at some point in their lives (Farghal et al., 2014).Benign ovarian lesions are found in about 1 in 25 gynaecologically asymptomatic women aged 20-39 years with no history of gynecological disease (Jokukiene et al., 2014).

Ovarian tumours are found either during the investigation of abdominal pain or as a result of imaging for other reasons (Zanetto et al., 2011). Due to the complex embryological and histogenetic development, the ovaries are the source of great variety of tumours (Jamal 1993). Ovarian cysts are usually functional cysts which resolve over a period of 6 months. Occasionally, they can persist for longer or grow in size to become a problem. There evolution can be followed by ultrasound. Nonfunctional cysts have diverse histologic origins. The most common are serous and mucinous cystadenomas which arise from epithelial wall of ovary. Endometriomas which arise in the setting of pelvic endometriosis and Dermoid cysts arise from germ cells of the ovary (Raiga et al., 2006) Paraovarian cysts are found in the broad ligament between the ovary and fallopian tube. They may be either nonneoplastic simple cysts or cysts of neoplastic origin. The simple paraovarian cysts originate from embryologic remnants of the urogenital system (The mesonephric and paramesonephric ducts) or from the invagination of tubal serosacreating a mesothelial cyst (Smorgick et al., 2009)

Ultrasonography plays the most important role in the diagnosis and management of women with benign ovarian tumours (Dupius et al., 2015). Laparoscopic surgery offers significant advantages such as reduced hospital stay, less adverse effects, better quality of life and superior vision especially on surgical treatment of cases like endometriosis (Grammaikakis et al., 2015).

Ovarian carcinoma is the second most common gynaecologic malignancy and is responsible for more 


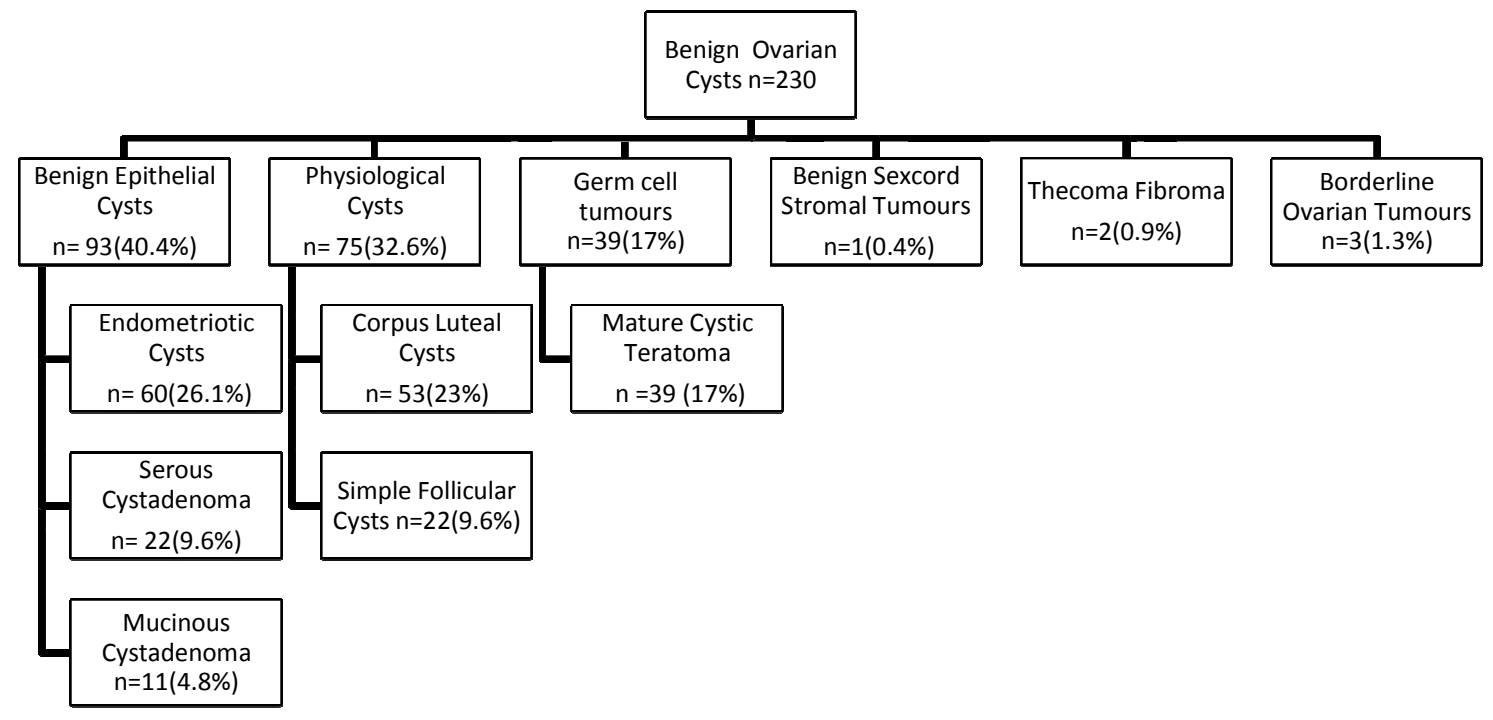

Figure 1: Graphical abstract of distribution of benign ovarian cysts in the study

deaths than endometrial and cervical carcinoma combined. Benign ovarian neoplasms have the capacity to undergo malignant change and are difficult to diagnose in early stages. Although rarely life threatening, they can cause patients considerable physical and psychological distress. In view of the high morbidity and mortality associated with ovarian tumours, We have carried out this study to find out the frequencies of different types of benign ovarian masses and their different characteristics including age distribution, racial distribution and laterality in the patients we come across at Al Ahli hospital especially considering the diverse races of patients we come across at Al Ahli Hospital.

\section{Patients and methods}

This study included 230 women who underwent surgery due to suspected ovarian or paraovarian cysts at Al Ahli hospital, Doha, Qatar between $1^{\text {st }}$ Jan 2013 and $31^{\text {st }}$ December 2015. Clinicopathological data was retrospectively collected from the patients hospital medical records. The records were analyzed in terms of demographic characteristics, nationalities, surgical intervention carried out, Laterality of the ovarian cyst and Histological diagnosis. This study was approved by the hospital research committee which is also responsible for ethical approval. Inclusion criteria included all patients who had gone surgical intervention and were discovered to have ovarian and paraovarian cysts. Exclusion criteria included patients with Asymptomatic, simple, echo free, unilocular, unilateral ovarian cysts without solid parts or papillary formations, and normal CA-125 levels that did not undergo surgical intervention and Ovarian cysts that had a high suspicion of being malignant as they do not undergo surgery at Al Ahli Hospital and are referred.

All statistical analysis were performed by IBM SPSS version 23.Variables included age in years, nationality, continental distribution, laterality of cysts, involved side and histopathological type. The mean and standard deviation was calculated for the continuous variables. Frequency and percentage of other nominal variables were also computed. Frequencies and percentages were calculated for each type of ovarian cysts and their distribution as unilateral, bilateral and the involvement of left or right ovary. The Pearson chi square test was used to find an association between the type of cyst and its distribution in the right and left ovary.

\section{RESULTS}

A total of 230 women from around 41 nationalities from around the world were found to have ovarian or paraovarian cysts. Asia 166 (72.2\%), Africa 29(12.6\%), Europe 19(8.3\%), North America 13(5.7\%), South America $1(0.4 \%)$ and Australia $1(0.4 \%)$. The age ranged between 14 to 58 years. The mean \pm standard deviation (SD) was $34.23 \pm 8.668$. The median age was 33 . Benign Epithelial tumours were the most common 93(40.4\%), followed by Physiological Cysts 75 (32.6\%), Benign Germ cell tumours $39(17 \%)$, Benign sex cord stromal tumours $1(0.4 \%)$ and The coma fibroma $2(0.9 \%)$. There were $3(1.3 \%)$ borderline ovarian tumours and Paraovarian cysts were $17(7.4 \%)$. Among the benign epithelial tumours Endometriotic cysts were 60(26.11\%), Serous 
Table 1: Distribution of benign ovarian tumours $(n=230)$

\begin{tabular}{|c|c|c|c|c|c|c|c|c|c|c|}
\hline HISTOPATHOLOGY & & & & eral & & & & & & \\
\hline & $\mathrm{n}$ & $\%$ & $\mathbf{n}$ & $\%$ & $\mathrm{n}$ & $\%$ & $\bar{n}$ & $\%$ & $\mathbf{n}$ & $\%$ \\
\hline Total & 230 & 100 & 200 & 87 & 110 & 47.8 & 90 & 39.1 & 30 & 13 \\
\hline Physiological Cysts & 75 & 32.6 & 67 & 89.3 & 41 & 54.7 & 26 & 34.7 & 8 & 10.7 \\
\hline Simple Follicular Cysts & 22 & 9.6 & 18 & 81.8 & 10 & 45.5 & 8 & 36.4 & 4 & 18.2 \\
\hline Corpus Luteal Cysts & 53 & 23 & 49 & 92.5 & 31 & 58.5 & 18 & 34 & 4 & 7.5 \\
\hline Benign Germ Cell Tumours & 39 & 17 & 31 & 79.5 & 17 & 43.6 & 14 & 35.9 & 8 & 20.5 \\
\hline Mature Cystic Teratoma & 39 & 17 & 31 & 79.5 & 17 & 43.6 & 14 & 35.9 & 8 & 20.5 \\
\hline Benign epithelai Tumours & 93 & 40.4 & 78 & 84 & 39 & 41.9 & 39 & 41.9 & 15 & 16.1 \\
\hline Serous Cystadenoma & 22 & 9.6 & 22 & 100 & 12 & 54.5 & 10 & 45.5 & 0 & 0 \\
\hline Mucinous Cystadenoma & 11 & 4.8 & 10 & 90.9 & 4 & 36.4 & 6 & 54.5 & 1 & 9.1 \\
\hline Endometrioid Cystadenoma & 60 & 26.1 & 47 & 78.3 & 23 & 38.3 & 24 & 40 & 13 & 21.7 \\
\hline Sex Cord Stromal Tumours & 1 & 0.4 & 0 & 0 & 1 & 0.4 & 0 & 0 & 0 & 0 \\
\hline Thecoma Fibroma Group & 2 & 0.9 & 0 & 0 & 0 & 0 & 2 & 0.9 & 0 & 0 \\
\hline Paraovarian Cyst & 17 & 7.4 & 17 & 100 & 9 & 52.9 & 8 & 47.1 & 0 & 0 \\
\hline Borderline Ovarian Tumours & 3 & 1.3 & 0 & 0 & 3 & 1.3 & 0 & 0 & 0 & 0 \\
\hline
\end{tabular}

Cystadenomas 22(9.6\%) and Mucinous Cystadenomas $11(4.8 \%)$. For Physiological cysts corpus luteal cysts were most common 53(23\%), simple follicular cysts were $22(9.6 \%)$. There was bilateral ovarian involvement in $30(13 \%)$ and unilateral ovarian involvement in 200(87\%). For unilateral cysts the right ovary was involved in 110 $(47.8 \%)$ and left ovary was involved in 90 (39.1\%). The ovarian cysts were managed by operative laparoscopy in $220(95.7 \%)$ of the women, Laparotomy in $2(0.9 \%)$. The ovarian cysts that were removed during a c section were $7(3 \%)$ and one $(0.4 \%)$ ovarian cyst was removed during a Total abdominal hysterectomy with bilateral salpingoopherectomy.

\section{DISCUSSION}

Our study included women were from 14 to 58 years from all regions of the world including Asia 166 (72.2\%), Africa 29(12.6\%), Europe 19(8.3\%), North America 13(5.7\%), South America 1(0.4\%) and Australia 1(0.4\%). Benign Epithelial tumours were the most common 93(40.4\%), followed by Physiological Cysts 75(32.6\%), Benign Germ cell tumours $39(17 \%)$, Benign sex cord stromal tumours $1(0.4 \%)$ and Thecoma fibroma $2(0.9 \%)$. There were $3(1.3 \%)$ borderline ovarian tumours and Paraovarian cysts were $17(7.4 \%)$. Among the benign epithelial tumours, Endometriotic cysts were 60(26.11\%) most common followed by Serous Cystadenomas 22(9.6\%) and Mucinous Cystadenomas 11(4.8\%). For Physiological cysts corpus luteal cysts were most common 53(23\%) and simple follicular cysts were $22(9.6 \%)$.In a study from Greece $80.6 \%$ of women had ovarian endometriosis, $3.3 \%$ had serous cystadenomas $2.9 \%$ had dermoid ovarian cyst, $2.5 \%$ borderline ovarian tumours, $2.3 \%$ unruptured follicles and $2.2 \%$ paraovarian cysts $^{8}$. In a study carried out in Saudi Arabia 79.9\% were ovarian cysts, $17.5 \%$ were paraovarian cysts or retroperitoneal cysts. Functional cysts were $33.2 \%$, benign cystadenoma $19.3 \%$ and dermoid cysts were 12.3\% (Abdul Jabber et al., 2015)

There was bilateral ovarian involvement in 30(13\%) and unilateral ovarian involvement in 200(87\%). For unilateral cysts the right ovary was involved in $110(47.8 \%)$ and left ovary was involved in 90 (39.1\%). In a study from Saudi Arabia right ovaries were involved in $63.1 \%$ and ovaries were bilaterally affected in $18.9 \%$ (Abdul Jabber et al., 2015). In the case of Physiological cysts, Simple follicular cysts were bilateral in $4(18.2 \%)$, and unilateral in $18(81.8 \%)$. Right ovary was involved in $10(45.5 \%)$ and left ovary in $8(36.4 \%)$. Corpus luteal cysts were bilateral in $4(7.5 \%)$ and unilateral in $49(92.5 \%)$. Right ovary was involved in 31(58.6\%) and left ovary in 18(34\%). Both the types of physiological cysts showed increased involvement of the right ovary.

In the case of Germ cell tumours, Mature cystic teratomas were bilateral in $8(20.5 \%)$ and unilateral in $31(79.5 \%)$. The right ovary was involved in $17(43.6 \%)$ and left ovary in 14 (35.9\%). There was minimal increased involvement of right ovary compared to left.

For epithelial tumours, All serous cystadenomas were found to be unilateral $22(100 \%)$, with right ovary involved in $12(54.5 \%)$ and left ovary involved in $10(45.5 \%)$. The increased involvement of right ovary was minimal. For mucinous cystadenomas $10(90.9 \%)$ were unilateral while $1(9.1 \%)$ was bilateral. Right ovary was involved in 
$4(36.4 \%)$ and left ovary was involved in 6(54.5\%). There was greater involvement of left ovary in mucinous cystadenomas. Endometriod cystadenomas were unilateral in $47(78.3 \%)$ and bilateral in 13(21.7\%). The right ovary was involved in $23(38.3 \%)$ and left ovary also 24 (40\%). Paraovarian cysts were all unilateral 17(100\%). The right ovary was involved in $9(52.9 \%)$ and left ovary in $8((47.1 \%)$.Showing almost equal chances of involvement of any one of the adnexal sides.

In one study on non endometriotic benign ovarian cysts left ovarian lesions were found in $50.4 \%$. Left sided ovary was involved in serous $48 \%$, mucinous $44 \%$, dermoid cysts $52.4 \%$ and $42.9 \%$ of the paraovarian cysts had involvement of left ovary (Vercillini et al., 2000).

In our study the endometriotic cysts had the highest tendency compared to all other cysts to be bilateral and the chances of left and right ovary to be involved was equal. In contrast a study carried out in Scandinavia showed that left ovarian involvement $(62.8 \%)$ was more frequent than right (Sznurkowski et al., 2008)

In Asians Physiological cysts were 47 (28.1\%). Simple follicular cysts were $17(10.2 \%)$ and corpus luteal cysts $30(18 \%)$. Mature cystic teratomas were 25(15\%). Epithelial tumours were 78(46.7\%), Serous cystadenomas were $20(12 \%)$, Mucinous cystadenomas were $10(6 \%)$ and endometroid cystadenomas $48(28.7 \%)$ Paraovarian cysts were 13(7.8\%). The endometroid cystadenomas were the largest in number followed by corpus luteal cysts and mature cystic teratomas. In an Iranian study Functional cysts were most common at $57 \%$ followed by serous cystadenomas (13\%) and dermoid cysts (10\%) (Arab et al., 2015).

In an Indian study Functional cysts were 12.5\%, Ovarian tumors were $70.5 \%$, Paraovarian and Para tubal cysts $10.7 \%$. Serous cystadenoma was the most common ovarian tumour at $59.5 \%$, followed by mucinous cystadenoma $20 \%$ andmature cystic teratomas were $14 \%$ (Manivasham et al., 2012).In another Indian study Serous cystadenoma $(67 \%)$ was the most common benign tumour followed by mucinous cystadenoma 19\%and dermoid cyst $11.6 \%$ (Shraddha et al., 2015).In a study from Nepal mature cystic teratoma was the most common benign ovarian tumour $(48.2 \%)$ (Jha et al., 2008).

Women with ovarian cysts from the African region were 29. Physiological cysts were found in 15 (51.7\%), corpus luteal cysts were $13(44.8 \%)$, follicular cysts were $2(6.9 \%)$. Mature cystic teratomas were found in $7(24 \%)$. Benign epithelial tumours were $5(17.2 \%)$, Mucinous cystadenoma $1(3.4 \%)$ and endometrioid cystadenomas $4(13.8 \%)$. The corpus luteal cysts were the most frequent ovarian cysts in African women. In a study from Nigeria mature cystic teratomas were the most common benign tumour accounting 60.1\% (Onyiaovah et al., 2011). There were 19 women from Europe and the most frequent ovarian cyst were the corpus luteal cyst $8(42.1 \%)$ followed by endometrioid cystadenomas 5(26.3\%), Mature cystic teratoma $4(21.1 \%)$ and simple follicular cysts $2(10.5 \%)$. In an Irish study the most common was endometrioma (29\%), Dermoid cyst (24\%) and functional cyst (19\%) (Alcazar et al., 2011).In an Italian study the most common ovarian tumour was an endometrioma (19\%) followed by functionalcysts (18\%) (Guerriero et al., 2009).

There were 13 women from North America. Mature cystic teratoma as found in $3(23.1 \%)$, Endometroid cystadenoma $3(23.1 \%)$, Paraovarian cysts in $3(23.1 \%)$, Serous cystadenoma in $2(15.4 \%)$, and corpus luteal cysts in $2(15.4 \%)$. There was 1 South American with a follicular cyst and 1 Australian with a Paraovarian cyst.

In Asian women Right ovary was involved in $77(46.1 \%)$, left ovary in $65(38.9 \%)$ and $25(15 \%)$ women had bilateral ovarian cysts. In African women all ovarian cysts were unilateral. Right ovarian involvement was $19(65.5 \%)$, left ovary $10(52.6 \%)$. In the women from Europe $2(10.5 \%)$ had bilateral cysts, Right ovary was involved in $7(36.8 \%)$, left ovary $(52.6 \%)$.

In women from North America 2(15.4\%) had bilateral ovarian cysts. Cysts were unilateral in $11(84.6 \%)$ with right ovarian cysts in $6(46.2 \%)$ and left ovarian cysts in $5(38.5 \%)$. The difference between the left and right ovarian involvement in case of endometriotic and non endometriotic cysts was statistically significant at $a x^{2}$ of 6.175 at $P$ value of 0.046 . In 7 women ovarian cysts were discovered and removed during caesarean section. The regional distribution was 6(85.7\%) from Asia and Africa $1(14.3 \%)$. Mature cystic teratoma was found in $2(28.6 \%)$, follicular cyst $1(14.3 \%)$, Serous cystadenoma $1(14.3 \%)$, Endometrioid cystadenoma $1(4.3 \%)$, Borderline serous tumour in $1(14.3 \%)$ and $1(14.3 \%)$ stromal cell tumour. The right ovary was involved in $5(71.4 \%)$ and left ovary was involved in 2 (28.6\%).

\section{CONCLUSION}

Benign epithelial tumors were most common and of them endometriotic cysts were most common followed by serous cystadenomas. These were followed by physiological cysts and mature cystic teratomas. Right ovarian involvement was significantly greater than left ovarian involvement.

This study involves women from all most all regions of the world. It gives an insight to some regional variation of the pattern of ovarian tumours in different regions of the world. However the women from Asia were greatest in number and less women were from other regions. The results for women from other regions besides Asia may not be applicable to the general population from these areas due to their less numbers. 


\section{REFERENCES}

AbdulJabber HS, Bukhari YA, Al Hachim EG, Ashour GS, Amer AA, Shaikhoun MM, Khojah MI (2015). Review of 244 cases of ovarian cysts.Saudi Med J.;36(7):834-8

Alcazar JL, Guerriero S, Laparte C, Ajossa S, Ruiz-Zambrana A, Melis GB (2011). Diagnostic performance of transvaginal gray-scale ultrasound for specific diagnosis of benign ovarian cysts in relation to menopausal status. Matruitas;68:182-188

Arab M, Hashmi M, Masoumi N, Yasei M, Golfam F, Ebrahim M (2015). Surgical Histopathology of Benign ovarian cysts: a multicenter study. Iranian J. pathology;5:132-6

Dupius CS, Kim YH (2015). Ultrasonography of adnexal causes of acute pelvic pain in premenopausal non-pregnant women. Ultrasonography; 34(4):258-267

Farghaly SA (2014). Current diagnosis and management of ovarian cyst.ClinExpObstetGynecol; 41(6):604-12

Grammaikakis I, Trompoukis P, Zervourdis S, Mavrelos C, Economides P, Tziortziotic V, Evangelinakis N, Kassanos D (2015). Laparoscopic treatment of 1522 adnexal masses: An 8 year experience. DiagTher Endosc.;2015-979162

Guerriero S, Alcazar JL, Pascual MA, Ajossa S, Gerada M, Bargellini R (2009). Diagnosis of the most frequent benign ovarian cysts: is ultrasonography accurate and reproducible? J. Women's Health (Larchmt); 18:519-27

Jamal S, Malik A, Ahmad M, Mushtaq S, Khan AH (1993). The pattern of malignant ovarian tumours- A study of 285 consecutive cases at the armed forces institute of pathology Rawalpindi. Pakistan J pathol; 4 : $107-10$
Jha R, Karhi S (2008). Histological pattern of ovarian tumours and their age distribution. Nepal Med Coll J;10(2):81-5

Jokukiene L, Sladkevicius P, Valentin L (2014). Prevalence of extrauterine pelvic lesions on transvaginal ultrasound in asymptomatic 20-39 year old women. Ultrasound ObstetGynecol ; 44(2) : 228-37

Manivasham J, Aroumassalame B (2012). A Study of benign adnexal masses.Int J ReprodContraceptObstetGynecol (1):12-6

Raiga J, Djeger R, Benoit B (2006).Tveisser .Management of ovarian cysts. J. de Chirurgie; 143(5): 278-84

Shraddha SO, Sridevi TA, Renukadein TK, Gowri R, Binayah D, Indra V (2015). Ovarian masses:Changing histopathological trends. J ObstetGynaecol India;65(1):34-8Smorgich Herman A, Schneider D, Halperin R, Pansky M (2009). Paraovarian cysts of neoplastic origin are underreported. JSLS, 13(1):22-26

Sznurkowski JJ, Emerich J (2008) Endometriomas are more frequent on left side .ActaObstetGynecolScand ; 87(1) : 104-6

Vercellini P, Pisacreta A, Vicentini S, Stellato G, Pesoli A, Crosignani PG (2000). Lateral distribution of non endometrotic benign ovarian cysts. BJOG;107(4):556-8

Zanetto U, Downey G (2011). p 668.Benign Tumours of the Ovary.In : Shaw R, Luesley D, Monga A. Gynaecology. $4^{\text {th }}$ Edition.Churchil Livingston Elsevier Ltd :668 